Nailis, H., Vandenbosch, D., Deforce, D., Nelis, H. \& Coenye, T. (2010). Transcriptional response to fluconazole and amphotericin B in Candida albicans biofilms. Res Microbiol 161:284-292.

\title{
Transcriptional response to fluconazole and amphotericin B in Candida albicans biofilms
}

'Laboratory of Pharmaceutical Microbiology, Ghent University, Harelbekestraat 72, B-9000, Gent, Belgium

' Laboratory of Pharmaceutical Biotechnology, Ghent University, Harelbekestraat 72,

20 E-mail adresses: heleen.nailis@ugent.be, davy.vandenbosch@ugent.be, dieter.deforce@ugent.be, hans.nelis@ugent.be, Tom.Coenye@ugent.be *"Correspondence and reprints"; Laboratory of Pharmaceutical Microbiology, Ghent University, Harelbekestraat 72, B-9000 Ghent, Belgium. Tel.: +32 926481 41; Fax: +3292648195. 


\section{Abstract}

Biofilm formation is often associated with persistent Candida albicans infections. Treatment of these infections is difficult since sessile $C$. albicans cells show an increased resistance towards antifungal agents. The molecular mechanisms behind biofilm resistance in $C$. albicans are not yet understood. In the present study, we investigated the transcriptional response in young and mature in vitro grown biofilms after a short and longer exposure time to high doses of fluconazole or amphotericin B. Treatment of biofilms with high doses of antifungal agents resulted in a drugspecific transcriptional response. Exposure of biofilms to fluconazole induced an upregulation of genes encoding enzymes involved in the ergosterol biosynthesis (ERG1, ERG3, ERG11 and ERG25). Treatment of biofilms with amphotericin B resulted in an overexpression of $K R E 1$ and $S K N 1$, two genes encoding proteins involved in the $\beta-1,6$-glucan biosynthesis. Our data indicate that sessile $C$. albicans cells show a controlled regulation of gene expression as they quickly mount a drugspecific transcriptional response in the presence of high doses of antifungal agents. These transcriptional changes suggest an upregulation of the ergosterol biosynthesis (fluconazole) and an upregulation of the $\beta-1,6-$ glucan biosynthesis (amphotericin $B$ ) in sessile $C$. albicans cells, that might contribute to a resistant biofilm phenotype.

Key-words: Candida albicans; biofilms; resistance; fluconazole; amphotericin B; gene expression; RT-quantitative PCR 


\section{Introduction}

Candida albicans is a commensal fungus of healthy human individuals that can cause superficial and systemic infections when the immune defences are repressed or when the normal microbial flora is disturbed (Odds, 1988). Various antifungal agents are used to treat these infections, including azoles and polyenes (Pappas et al., 2004). Fluconazole (FLC) belongs to the azoles and interferes with the ergosterol biosynthesis by binding to the ERG11 gene product, lanosterol 14- $\alpha$-demethylase (Richardson, 1990). The latter enzyme is crucial for ergosterol production, and inhibition of its activity results in disruption of the cell membrane leading to growth inhibition of the fungus (Kelly et al., 1993). It is known that long-term, low level use of FLC results in the development of azole resistance in C. albicans (Franz et al., 1998). Amphotericin B (AMB) is a member of the polyene family (Warnock, 1991). This molecule binds to ergosterol and forms pores resulting in a disorganized membrane with increased permeability (Brajtburg et al., 1990). In addition, AMB induces cell damage by generating lethal reactive oxygen species (Brajtburg et al., 1990). Development of resistance against this antifungal agent has also been reported, but is less frequent (Ellis, 2002).

The molecular mechanisms of antifungal resistance in $C$. albicans have been well studied and changes in gene expression have frequently been reported in resistant clinical isolates (Sanglard, 2002; White, 1997; White et al., 1998). FLC resistance in particular is associated with overexpression of ERG11 (Franz et al., 1998; LopezRibot et al., 1998). Changes in the expression of other ERG genes such as ERG3 and ERG25 have also been observed (Henry et al., 2000). In addition, genes encoding efflux pumps (MDR1, CDR1 and CDR2) are often upregulated in FLCresistant isolates (Lopez-Ribot et al., 1998; Rogers and Barker, 2003; White et al., 
2002). Upregulation of $E R G$ genes and of genes encoding efflux pumps were also detected in planktonic cells after exposure to FLC in vitro (Hernáez et al., 1998; Lepak et al., 2006). In vitro exposure of planktonic cells to AMB is correlated with underexpression of ERG3 and ERG11, indicating that changes in the sterol composition are important for AMB resistance in C. albicans (Liu et al., 2005). Furthermore, changes in the $\beta-1,6$-glucan biosynthesis have also been proposed as a resistance mechanism against $\mathrm{AMB}$ (Gale, 1986). SKN1 and KRE1, two genes involved in the $\beta$-1,6-glucan biosynthesis (Mio et al., 1997) were found to be differentially expressed after in vitro exposure of $C$. albicans planktonic cells to caspofungin, but not to AMB (Liu et al., 2005).

C. albicans infections are often associated with the formation of biofilms (Douglas, 2003); biofilms are three-dimensional structures of yeast cells and filaments that are embedded in an extracellular matrix (Kumamoto, 2002). Sessile C. albicans cells (cells in a biofilm) are phenotypically different from planktonic cells (cells that are not attached to a surface), with one of the most prominent features being the increased resistance towards antifungal agents (Chandra et al., 2001; Hawser and Douglas, 1995). Therefore, eradication of biofilms and treatment of the associated infections are very difficult (Kuhn and Ghannoum, 2004). In order to develop novel and effective anti-biofilm strategies it is essential to understand the molecular mechanisms of biofilm resistance. However, antifungal resistance in $C$. albicans biofilms is a complex phenomenon, and multiple mechanisms are likely to be involved (Kuhn and Ghannoum, 2004). It has been reported that genes encoding efflux pumps are highly expressed in young biofilms (Mateus et al., 2004; Mukherjee et al., 2003; Ramage et al., 2002), while reduced ergosterol levels provide a possible resistance mechanism 100 in mature biofilms (Mukherjee et al., 2003). Furthermore, the presence of resistant 
subpopulations in biofilms in the absence of antifungal agents has also been proposed as a cause of intrinsic biofilm resistance (Khot et al., 2006). Recently, it was demonstrated that the majority of the biofilm population was killed after exposure to high doses of $\mathrm{AMB}$, and that only a small fraction of cells (persisters) survives the 105 treatment (LaFleur et al., 2006). However, at present it is not known which mechanisms sessile cells use to survive in the presence of high doses of antifungal agents. Investigating the molecular mechanisms of resistance in persisters will help to understand resistance in $C$. albicans biofilms.

The goal of the present study was to investigate the expression of genes, known to 110 be regulated in response to antifungal agents in planktonic cells or known to be expressed in resistant strains, in $C$. albicans biofilms. For this, young $(0.5 \mathrm{~h}$ and $1 \mathrm{~h})$ and mature (24 h and $72 \mathrm{~h}$ ) biofilms were grown after a short $(1 \mathrm{~h})$ and longer $(22 \mathrm{~h})$ exposure time to high doses of FLC or AMB, and also after removal of the antifungal drugs. The expression of genes encoding efflux pumps (MDR1, CDR1 and CDR2),

115 genes encoding enzymes involved in the ergosterol biosynthesis (ERG1, ERG3, ERG11 and ERG25) and genes encoding proteins involved in the $\beta$-1,6-glucan biosynthesis (KRE1 and SKN1) were quantified, using RT-qPCR (Reverse Transcriptase quantitative PCR). 


\section{Materials and Methods}

C. albicans strain SC5314 (American Type Culture Collection MYA-2876) was used throughout the study. Cells were stored at $-80{ }^{\circ} \mathrm{C}$ in Microbank tubes (Prolab Diagnostics, Ontario, Canada) and routinely transferred to Sabouraud Dextrose Agar plates (SDA; Oxoid, Hampshire, UK). These were incubated at $37^{\circ} \mathrm{C}$ for $24 \mathrm{~h}$.

\subsection{Biofilm growth}

C. albicans SC5314 biofilms were grown on silicone disks in 24-well microtiter plates (TPP, Trasadingen, Switzerland). Silicone sheets were prepared from a medical grade silicone rubber kit (Q7-4735; Dow Corning Corp., Midland, MN, USA) according to the manufacturer's instructions. Thirteen-millimetre diameter disks were punched from the sheets, subsequently washed with a detergent (2\% RBS35 solution; Sigma, St. Louis, MO, USA), rinsed with MilliQ water (Millipore, Billerica, MA, USA) and heat-sterilized. Start cultures were prepared by incubating $C$. albicans cells for $16 \mathrm{~h}$ in Sabouraud Dextrose Broth (SDB; Oxoid, Hampshire, UK) at $37^{\circ} \mathrm{C}$ in

135 a water bath with shaking; cells were subsequently washed three times with and finally resuspended in $1 \mathrm{ml} 0.9 \%$ (w/v) $\mathrm{NaCl}$. A $0.4 \%$ cell suspension was prepared in Yeast Nitrogen Base (YNB; BD, Franklin Lakes, NJ, USA) supplemented with 50 mM glucose (Sigma, St. Louis, MO, USA); this cell suspension contains approx. 5\% filaments (Nailis et al., 2009). One $\mathrm{ml}$ of this suspension was added to each well and

140 plates were incubated for $30 \mathrm{~min}(0.5 \mathrm{~h}$ old biofilms $)$ or $1 \mathrm{~h}$ at $37^{\circ} \mathrm{C}$. Silicone disks were then washed three times with $1 \mathrm{ml} 0.9 \%(\mathrm{w} / \mathrm{v}) \mathrm{NaCl}$ to remove non-adherent cells. Disks were placed in new plates, $1 \mathrm{ml}$ diluted YNB (1:5; final glucose concentration: $10 \mathrm{mM}$ ) (YNB 0.2x) was added to each well and plates were further 
incubated for $24 \mathrm{~h}$ or $72 \mathrm{~h}$ at $37^{\circ} \mathrm{C}$. Biofilm structures were visualized using confocal

145 laser scanning microscopy (CLSM), as described previously (Nailis et al., 2009).

\subsection{Antifungal agents}

Diflucan ${ }^{\circledR}$ (Pfizer, New York, NY, USA) and Fungizone ${ }^{\circledR}$ (Bristol-Myers Squibb, New York, NY, USA) were the pharmaceutical formulations used. Diflucan contains 2000 $\mathrm{mg} / \mathrm{l}$ of FLC. Fungizone contains AMB powder that was dissolved in MilliQ water and further diluted to obtain stock solutions of $64 \mathrm{mg} / \mathrm{l}$. Aliquots of both antifungal agents were stored at $-80^{\circ} \mathrm{C}$. The minimal inhibitory concentrations (MICs) of FLC and AMB were determined according to the European Committee for Antimicrobial Susceptibility Testing (EUCAST) procedure (Cuenca-Estrella et al., 2003).

\subsection{Treatment of biofilms with antifungal agents}

Biofilms were grown as described above. Silicone disks were subsequently transferred to new 24-well microtiter plates, and antifungal agents were added (final concentration of $1000 \mathrm{mg} / \mathrm{l}$ for FLC and $32 \mathrm{mg} / \mathrm{l}$ for $\mathrm{AMB}$, in buffered antifungal-free

160 medium). RPMI-1640 2x supplemented with $200 \mathrm{mM}$ glucose and buffered to $\mathrm{pH} 7.0$ with 330 mM MOPS (Sigma, St. Louis, MO, USA) was used for this purpose. Control biofilms were grown in buffered RPMI without antifungal agents. Plates were incubated at $37^{\circ} \mathrm{C}$ for $1 \mathrm{~h}$ or $22 \mathrm{~h}$, after which cells were washed three times with $0.9 \%(\mathrm{w} / \mathrm{v}) \mathrm{NaCl}$. For the regrowth experiments, biofilms were treated for $22 \mathrm{~h}$ after

165 which they were washed five times with $1 \mathrm{ml}$ of $0.9 \%(\mathrm{w} / \mathrm{v}) \mathrm{NaCl}$, and disks were transferred to new 24-well microtiter plates. One ml of buffered RPMI was added to the wells and plates were further incubated up to $24 \mathrm{~h}$ at $37^{\circ} \mathrm{C}$. 


\subsection{Cell quantification}

170 To enumerate the number of culturable sessile cells, plating was used. Silicone disks were transferred to $10 \mathrm{ml} \mathrm{SDB}$ and cells were subjected to three cycles of $30 \mathrm{~s}$ sonication (Branson 3510, 42 kHz, 100 W; Branson Ultrasonics Corp., Danbury, CT, USA) and $30 \mathrm{~s}$ vortex mixing. Using this procedure, all cells were removed from the silicone and clumps of cells were broken apart, while viability and culturability of cells

175 were not affected (data not shown). Serial tenfold dilutions of the resulting cell suspensions were plated on SDA and plates were incubated for $24 \mathrm{~h}$ at $37^{\circ} \mathrm{C}$, after which colonies were counted. The experiments were performed at least in triplicate (independent biofilm experiments; biological replicates) with 4 disks per biofilm experiment (technical replicates) $(n \geq 12)$. Independent sample t-tests were carried

180 out using SPSS 15.0 software to determine whether differences were statistically significant $(p<0.05)$. Reductions were considered biologically relevant when a statistically significant reduction $(p<0.05)$ of at least $1 \log _{10}$ unit was observed.

\section{6. $R T-q P C R$}

185 Biofilms were grown and treated with antifungal agents as described above. Biofilms were then washed with $1 \mathrm{ml} 0.9 \%(\mathrm{w} / \mathrm{v}) \mathrm{NaCl}$, and subjected to sonication and vortex mixing as described above. RNA extraction, cDNA synthesis and RT-qPCR were performed as described previously (Nailis et al., 2006). Experiments were carried out in triplicate using starting material from independent biofilm experiments (biological 190 replicates). Full-length gene sequences were obtained from the $C$. albicans database (http://www-sequence.stanford.edu/group/candida/search.html). Primers and MGB Taqman probes were designed using Primer Express software (Applied Biosystems, Foster City, CA, USA). Sequences of the primers and MGB Taqman probes 
designed in the present study are listed in Table 1. The sequences of the primers and probes for the reference genes have been reported previously (Nailis et al., 2006). RT-qPCR data were normalized by geometric averaging of five internal reference genes. ACT1, RIP, RPP2B, PMA1 and LSC2 were used for this purpose as they have previously shown to be stably expressed in $C$. albicans biofilms (Nailis et al., 2006). Following normalization, normalized relative quantities were used to 200 calculate relative gene expression levels as described previously (Nailis et al., 2006). Gene expression levels (fold over- or underexpression) in biofilms in the absence of antifungal agents were calculated as the expression of a gene in biofilms, relative to its expression in start cultures (planktonic cells grown for $16 \mathrm{~h}$ in SDB at $37^{\circ} \mathrm{C}$ ). Gene expression levels (fold up- or downregulation) in biofilms treated with antifungal 205 agents were calculated as the expression of a gene in biofilms treated with FLC or $A M B$, relative to its expression in untreated biofilms. Gene expression levels (fold upor downregulation) in biofilms after removal of the antifungal agent were calculated as the expression of a gene in biofilms after regrowth, relative to its expression in biofilms after treatment. Confidence intervals were calculated to determine whether 210 differences in gene expression were statistically significant between two biological conditions $(p<0.05)$. 


\section{Results and Discussion}

\subsection{Biofilm formation on silicone disks in microtiter plates}

Young biofilms contained $2.5 \times 10^{4} \mathrm{CFU} /$ disk after $0.5 \mathrm{~h}$ and $5.0 \times 10^{4} \mathrm{CFU} /$ disk after 1

$215 \mathrm{~h}$, whereas mature biofilms contained $6.3 \times 10^{6} \mathrm{CFU} /$ disk (Table 2). CLSM analysis of a $1 \mathrm{~h}$ old biofilm showed mainly yeast cells that were adhered to the silicone surface (Fig. 1A). After $24 \mathrm{~h}$ (Fig. 1B) and $72 \mathrm{~h}$ (data not shown) biofilms showed a threedimensional structure of mainly yeast cells and few filaments, embedded in an extracellular matrix. Similar structures were obtained in previous studies (Chandra et

220 al., 2001; Zhao et al., 2006), although we observed less filaments. This is likely due to differences in growth conditions as we used YNB for biofilm growth in our model system. Previous studies frequently use abiotic surfaces that are incubated with fetal bovine serum prior to biofilm formation; serum is known to induce filamentation in $C$. albicans (Ponton et al., 1994).

\subsection{Effect of antifungal agents on pre-grown biofilms}

In the present study, we wanted to determine whether the age of the biofilm affects the activity of antifungal agents and whether this anti-biofilm activity is dependent on the exposure time. For this, we used very high doses of FLC (1000 mg/l; 8000 times the MIC) and AMB (32 mg/l: 256 times the MIC). These concentrations were selected because they resulted in the survival of only a small fraction of cells (AMB) or because they resulted in tolerance (FLC) for mature biofilms. No antifungal effect was observed after treatment of mature biofilms with FLC for $1 \mathrm{~h}$ or $22 \mathrm{~h}$, indicating that mature biofilms are tolerant to high doses of FLC (Table 2); this confirms previous observations (Chandra et al., 2001; Hawser and Douglas, 1995; Mukherjee et al., 2003; Ramage et al., 2002). Prolonged incubation with FLC (up to $144 \mathrm{~h}$ ) did 
not result in a reduction in cell number (data not shown). However, when young biofilms $(0.5 \mathrm{~h}$ and $1 \mathrm{~h})$ were treated for $22 \mathrm{~h}$ with FLC, only approx. $2.5 \times 10^{4} \mathrm{CFU}$ were recovered from the silicone disks (Table 2). Prolonged incubation of young 240 biofilms with high doses of FLC resulted in a reduction in cell number as approx. $3.2 \times 10^{3}$ CFU per disk were recovered after $144 \mathrm{~h}$. These findings indicate that high doses of FLC have an antifungal effect on young biofilms. Previous studies demonstrated that adherent $C$. albicans cells are as tolerant to FLC as mature biofilms, but in these studies lower FLC concentrations $(\leq 256 \mathrm{mg} / \mathrm{l})$ were used

245 (Mateus et al., 2004; Mukherjee et al., 2003).

Treatment of mature biofilms for $22 \mathrm{~h}$ with $32 \mathrm{mg} / \mathrm{l}$ of $\mathrm{AMB}$ resulted in a $99.5 \%$ reduction in cell number, indicating that only a small fraction of cells, likely "persisters", survived the treatment (Table 2) $(p<0.05)$. AMB was already found to show activity against mature biofilms at a concentration of $\geq 1 \mathrm{mg} / \mathrm{l}$ (Chandra et al., 250 2001; Hawser and Douglas, 1995; Kuhn et al., 2002), and exposure of mature biofilms to high doses of this antifungal agent is known to result in the survival of persisters (LaFleur et al., 2006). Recently, it was demonstrated that the presence of persisters in $C$. albicans biofilms is strain-dependent, and that biofilms formed by $C$. albicans strain SC5314 contain a very low fraction of persisters only after exposure to $50 \mathrm{mg} / \mathrm{l}$ of $\mathrm{AMB}$ (Al-Dhaheri and Douglas, 2008). However, different methods for biofilm growth were used, and this could explain why we were able to detect persisters in $C$. albicans SC5314 biofilms after treatment with $32 \mathrm{mg} / \mathrm{l}$ of AMB. Combined, these findings indicate that the presence of persisters in $C$. albicans biofilms is not only strain-dependent, but also seems to be dependent on the biofilm model system used. A short exposure of mature biofilms to AMB also resulted in the presence of persisters, as similar reductions in cell number were observed after $1 \mathrm{~h}$ 
and after $22 \mathrm{~h}$ of treatment (Table 2). Longer treatment (up to $144 \mathrm{~h}$ ) did not result in more eradication (data not shown). When young biofilms ( $1 \mathrm{~h}$ old) were treated with AMB for $1 \mathrm{~h}$ or $22 \mathrm{~h}$, approx. 99.5 and $96.8 \%$ of the population was killed,

265 respectively (Table 2). Similar results were obtained for young biofilms grown for 0.5 h (Table 2). Thus, irrespective of the age of the biofilm, a similar fraction of the cell population survives treatment with high doses of AMB. Chandra et al. (2001) found that resistance to $\mathrm{AMB}$ develops at later stages of biofilm formation. However, these authors used different biofilm growth conditions, different susceptibility methods and

270 lower concentrations of AMB (Chandra et al., 2001), which likely explain the observed discrepancies. Taken together, our data show that a small fraction (1 to 4 $\%$ ) of persisters are present in both young and mature biofilms, even after a short exposure to $A M B$.

CLSM analysis confirmed our findings as treatment of $72 \mathrm{~h}$ old biofilms with FLC for $22 \mathrm{~h}$ has no effect (Fig. 1C), while exposure to AMB for $22 \mathrm{~h}$ resulted in a disruption of the three-dimensional structure and a reduction in cell number (Fig. 1D). For AMB, similar results were obtained in a previous study (Hawser and Douglas, 1995).

\subsection{Gene expression in biofilms in the absence of antifungal agents}

280 In a next set of experiments, gene expression was quantified in biofilms relative to gene expression in start cultures (prior to treatment with antifungal agents). By doing so, we observed a marked overexpression of SKN1 in young biofilms; this gene was $27.0 \pm 13.5$ and $22.1 \pm 13.8$ (mean \pm SEM) fold upregulated after $0.5 \mathrm{~h}$ and $1 \mathrm{~h}$ of biofilm growth, respectively. Upregulation of SKN1 suggests a reorganization of the

$285 \beta-1,6-$ glucan content in the cell wall, a mechanism which is known to be implicated in transient AMB resistance in C. albicans (Gale, 1986; Liu et al., 2005). Khot et al. 
(2006) recently found that the expression of SKN1 was induced in a subpopulation of cells which are most closely in contact with the silicone surface. The majority of cells in a young biofilm grown in our model system are also in intimate contact with the silicone surface (see Fig. 1A). Combined, these data suggest that contact sensing with the silicone surface induces the expression of SKN1, which may render sessile C. albicans cells resistant to AMB even in the absence of antifungal drugs. On the other hand, overexpression of $S K N 1$ could be a sign of biofilm growth as this gene is highly upregulated only in young biofilms.

295 No statistical significant changes in the expression of genes encoding efflux pumps, nor in KRE1 or ERG gene expression were observed between biofilms and start cultures (data not shown). However, previous studies showed that MDR1, CDR1, CDR2 are overexpressed in young biofilms (Mateus et al., 2004; Mukherjee et al., 2003; Ramage et al., 2002). Discrepancies between these studies and our results are likely due to the fact that we detected a high number of transcripts for MDR1, $C D R 1, C D R 2$ (evidenced by low cycle threshold values) not only in young biofilms but also in start cultures (data not shown). Similarly to Mukherjee et al (2003), we detected lower gene expression levels for CDR1 and MDR1 after $24 \mathrm{~h}$ of biofilm growth than after $1 \mathrm{~h}(\mathrm{p}<0.05)$, confirming that the expression of genes encoding efflux pumps is higher in young biofilms.

\subsection{Transcriptional response to FLC in biofilms}

We also investigated gene expression in biofilms in the presence of high doses of FLC. Gene expression in biofilms treated with high doses of FLC was compared to

310 gene expression in untreated biofilms, and results are listed in Table 3. After $1 \mathrm{~h}$ of treatment with high doses of FLC, young biofilms showed an upregulation of ERG25, 
while in mature biofilms an overexpression of ERG1, ERG3, ERG11 and ERG25 was observed. After longer treatment, upregulation of $E R G$ genes was more pronounced in young biofilms, but not in mature biofilms (Table 3). It is possible that the response of $E R G$ gene expression in $24 \mathrm{~h}$ old biofilms is attenuated because mature biofilms are tolerant to high doses of FLC. However, we observed a high upregulation of $E R G$ genes in tolerant $72 \mathrm{~h}$ old biofilms after $22 \mathrm{~h}$ of treatment with high doses of FLC. In order to better understand the role of ERG gene expression in tolerance and sensitivity in biofilms, we examined gene expression in young biofilms treated with $0.5 \mathrm{mg} / \mathrm{l}$ of FLC. Young biofilms were tolerant to low doses of FLC as a mature biofilm with approx. $2.0 \times 10^{6} \mathrm{CFU}$ per disk was obtained after $22 \mathrm{~h}$ of treatment. As can be seen in Fig. 2, ERG genes were overexpressed in tolerant young biofilms, although the fold upregulations were lower than those observed in young biofilms after exposure to high doses of FLC. Upregulation of ERG genes was previously

325 observed in planktonic cells after in vitro exposure to FLC (Lepak et al., 2006) and also after exposure to another azole, itraconazole (De Backer et al., 2001). Combined, these data suggest a general response of the expression of $E R G$ genes to FLC sensing in biofilms and planktonic cells. The overexpression of ERG genes is probably related to biofilm resistance, but is not sufficient as sensitive biofilms show a similar gene expression pattern as tolerant biofilms.

Surprisingly, no statistical significant overexpression of genes encoding efflux pumps were observed in biofilms after exposure to high doses of FLC (Table 3). Similar results were obtained after treatment of planktonic cells with itraconazole (De Backer et al., 2001). However, when planktonic cells were exposed to FLC an upregulation

335 of CDR1 was observed (Hernáez et al., 1998). In the current study, an overexpression of CDR2 was found in tolerant young biofilms (Fig. 2), suggesting 
that efflux pumps play a role in biofilm resistance in a dose-dependent manner. Furthermore, we observed an overexpression of KRE1 and SKN1 in young biofilms after exposure to low doses of FLC (Fig. 2). This could be a sign of biofilm growth as SKN1 was also induced in young biofilms in the absence of antifungal agents (see above).

Together, the current study showed an upregulation of genes encoding enzymes involved in the ergosterol biosynthesis in sessile cells in the presence of FLC. This transcriptional response may contribute to biofilm resistance in C. albicans.

\subsection{Transcriptional response to $A M B$ in biofilms}

We also investigated gene expression in biofilms in the presence of high doses of AMB. Gene expression in biofilms treated with $A M B$ was compared to gene expression in untreated biofilms, and results are listed in Table 4. No statistical significant differences in the expression of ERG3, ERG11 and ERG25 were observed between biofilms exposed to AMB and untreated biofilms. A marked overexpression of SKN1 was seen in young and mature biofilms already after $1 \mathrm{~h}$ of exposure (Table 4), and its expression was even more induced after 22 h. Furthermore, KRE1 was significantly upregulated in young biofilms ( $1 \mathrm{~h}$ old) after $1 \mathrm{~h}$ of treatment, and in mature biofilms (24 h old) both after $1 \mathrm{~h}$ and $22 \mathrm{~h}(\mathrm{p}<0.05)$. In addition, ERG1 was significantly overexpressed in biofilms after $22 \mathrm{~h}$ of treatment $(\mathrm{p}<0.05)$. As mentioned above, exposure of biofilms to high doses of AMB resulted in the survival of a small fraction of cells, and these persisters seem to exhibit high expression levels of SKN1 (and to a lesser extent KRE1 and ERG1). Khot et al. (2006) demonstrated that SKN1 and KRE1 were highly upregulated in biofilms in the absence of AMB. Overexpression of SKN1 and KRE1 suggest changes in cell wall maintenance, which 
in turn could explain the high resistance of biofilms towards AMB (Gale, 1986; Liu et al., 2005). Consequently, overexpression of both genes could be responsible for the resistant phenotype of persisters in the presence of high doses of $A M B$ on the one hand, and also for the intrinsic resistance of biofilms in the absence of AMB on the other hand (our data and those from Khot et al. [2006]). It has already been demonstrated that planktonic cells show a downregulation of ERG3, ERG11 and ERG25 after exposure to much lower concentrations of AMB (Liu et al., 2005), indicating that biofilms show a specific transcriptional response to AMB. Based on our findings, changes in cell wall maintenance could be an important resistance mechanism in sessile $C$. albicans cells towards AMB.

\subsection{Transcriptional response to removal of the antifungal agent}

To test whether the transcriptional response in biofilms after exposure to antifungal

375 agents was transient or permanent, gene expression was investigated in biofilms after removal of FLC and AMB. For this, biofilms were grown for $72 \mathrm{~h}$, subsequently treated with antifungal drugs for $22 \mathrm{~h}$, and further incubated in antifungal-free medium. As can be seen in Table 5, biofilms showed a marked overexpression of SKN1 after removal of FLC. This gene was $49.6 \pm 9.2$ and $31.7 \pm 6.6$ (mean \pm SEM)

380 fold upregulated after $1 \mathrm{~h}$ and $24 \mathrm{~h}$ of regrowth, respectively. Overexpression of SKN1 could be a sign of biofilm regrowth as this gene was also upregulated during biofilm formation (see above). Furthermore, the expression of $E R G$ genes remained unchanged (Table 5), demonstrating that these genes were still upregulated $24 \mathrm{~h}$ after removal of FLC. A transient molecular response with upregulation of ERG11,

385 CDR1 and CDR2 in the presence of FLC and a downregulation of ERG11 in the post-exposure period has been observed in planktonic cells (Henry et al., 2000; 
Lepak et al., 2006). After removal of AMB, gene expression remained unchanged in biofilms, except for SKN1; this gene was $4.6 \pm 1.2$ (mean \pm SEM) fold upregulated 1 $\mathrm{h}$ after removal of the antifungal agent (Table 5). Our data indicate that the expression of SKN1 is highly induced in C. albicans persisters after exposure to $\mathrm{AMB}$, and that this gene remains upregulated in biofilms after removal of the antifungal agent.

\subsection{Concluding remarks}

395 In the present study, it was demonstrated that high doses of FLC have an antifungal effect on young biofilms, while mature biofilms were tolerant to this antifungal agent. Treatment of young and mature biofilms with high doses of AMB resulted in the survival of a small fraction (0.5 to $4 \%$ ) of persisters. Exposure of biofilms to FLC resulted in an overexpression of genes encoding enzymes involved in the ergosterol biosynthesis. However, genes encoding efflux pumps were not regulated in biofilms in response to high doses of FLC. Treatment of biofilms with high doses of AMB resulted in an upregulation of genes encoding proteins involved in the $\beta-1,6$-glucan biosynthesis. Transcriptional changes in sessile $C$. albicans cells in the presence of antifungal agents suggest an upregulation of the associated biosynthetic pathways,

405 thereby contributing to a resistant biofilm phenotype. Future research will provide a direct elucidation of these resistance mechanisms in sessile $C$. albicans cells. Taken together, our data indicate that young and mature biofilms show a rapid and antifungal-specific transcriptional response to exposure with FLC and AMB. This molecular adaptation could help to explain the high resistance of $C$. albicans biofilms towards antifungal agents. 


\section{Acknowledgements}

We are grateful to Alistair Brown (Aberdeen University, UK) for sharing C. albicans SC5314 with us. We would like to acknowledge Leen Molderez and Marlies De Kezel for technical assistance. We are grateful to Jo Vandesompele for providing useful

415 advice concerning qPCR data analysis. We kindly acknowledge Ine Lentacker, Kevin Braeckmans, Stefaan Desmedt and Jo Demeester for the use of the CLSM facilities. This work was funded by the Belgian Federation against Cancer and the FWO (Fonds voor Wetenschappelijk Onderzoek). 


\section{References}

420 1. Al-Dhaheri, R.S., Douglas, L.J., 2008. Absence of amphotericin B-tolerant persister cells in biofilms of some Candida species. Antimicrob. Agents Chemother. 52, 1884-1887.

2. Brajtburg, J., Powderly, W.G., Kobayashi, G.S., Medoff, G., 1990. Amphotericin B: Current understanding of mechanisms of action. Antimicrob. Agents Chemother. 34, 425 183-188.

3. Chandra, J., Kuhn, D.M., Mukherjee, P.K., Hoyer, L.L., McCormick, T., Ghannoum, M.A., 2001. Biofilm formation by the fungal pathogen Candida albicans: development, architecture, and drug resistance. J. Bacteriol. 183, 5385-5394.

4. Cuenca-Estrella, M., Moore, C.B., Barchiesi, F., Bille, J., Chryssanthou, E., 430 Denning, D.W., Donnelly, J.P., Dromer, F., Dupont, B., Rex, J.H., Richardson, M.D., Sancak, B., Verweij, P.E., Rodriguez-Tudela, J.L.; AFST Subcommittee of the European Committee on Antimicrobial Susceptibility Testing, 2003. Multicenter evaluation of the reproducibility of the proposed antifungal susceptibility testing method for fermentative yeasts of the Antifungal Susceptibility Testing Subcommittee 435 of the European Committee on Antimicrobial Susceptibility Testing (AFST-EUCAST). Clin. Microbiol. Infect. 9, 467-474.

5. De Backer, M.D., Ilyina, T., Ma, X.J., Vandonink, S., Luyten, W.H., Vanden Bossche, H., 2001. Genomic profiling of the response of Candida albicans to itraconazole treatment using a DNA microarray. Antimicrob. Agents Chemother. 45, 440 1660-1670.

6. Douglas, L.J., 2003. Candida biofilms and their role in infection. Trends Microbiol. 11, 30-36.

7. Ellis, D., 2002. Amphotericin B: spectrum and resistance. J. Antimicrob. Chemother. 49, 7-10.

445 8. Franz, R., Kelly, S.L., Lamb, D.C., Kelly, D.E., Ruhnke, M., Morschhäuser, J., 1998. Multiple molecular mechanisms contribute to a stepwise development of fluconazole resistance in clinical Candida albicans strains. Antimicrob. Agents Chemother. 42, 3065-3072.

9. Gale, E.F., 1986. Nature and development of phenotypic resistance to 450 amphotericin B in Candida albicans. Adv. Microb. Physiol. 27, 277-320.

10. Hawser, S.P., Douglas, L.J., 1995. Resistance of Candida albicans biofilms to antifungal agents in vitro. Antimicrob. Agents Chemother. 39, 2128-2131. 
11. Henry, K.W., Nickels, J.T., Edlind, T.D., 2000. Upregulation of ERG genes in Candida species by azoles and other sterol biosynthesis inhibitors. Antimicrob. Agents Chemother. 44, 2693-2700.

12. Hernáez, M.L., Gil, C., Pla, J., Nombela, C., 1998. Induced expression of the Candida albicans multidrug resistance gene CDR1 in response to fluconazole and other antifungals. Yeast. 14, 517-526.

13. Kelly, S.L., Arnoldi, A., Kelly, D.E., 1993. Molecular genetic analysis of azole 460 antifungal mode of action. Biochem. Soc. Trans. 21, 1034-1038.

14. Khot, P.D., Suci, P.A., Miller, R.L., Nelson, R.D., Tyler, B.J., 2006. A small subpopulation of blastospores in Candida albicans biofilms exhibit resistance to amphotericin $B$ associated with differential regulation of ergosterol and bèta-1,6glucan pathway genes. Antimicrob. Agents Chemother. 50, 3708-3716.

465 15. Kuhn, D.M, George, T., Chandra, J., Mukherjee, P.K., Ghannoum, M.A., 2002. Antifungal susceptibility of Candida biofilms: unique efficacy of amphotericin B lipid formulations and echinocandins. Antimicrob. Agents Chemother. 46, 1773-1780.

16. Kuhn, D.M., Ghannoum, M.A., 2004. Candida biofilm: antifungal resistance and emerging therapeutic options. Curr. Opin. Investig. Drugs. 5, 186-197.

470 17. Kumamoto, C.A., 2002. Candida biofilms. Curr. Opin. Microbiol. 5, 608-611.

18. LaFleur, M.D., Kumamoto, C.A., Lewis, K., 2006. Candida albicans biofilms produce antifungal-tolerant persister cells. Antimicrob. Agents Chemother. 50, 38393846.

19. Lepak, A., Nett., J., Lincoln, L., Marchillo, K., Andes, D., 2006. Time course of 475 microbiologic outcome and gene expression in Candida albicans during and following in vitro and in vivo exposure to fluconazole. Antimicrob. Agents Chemother. 50, 1311-1319.

20. Liu, T.T., Lee, R.E., Barker, K.S., Lee, R.E., Wei, L., Homayouni, R., Rogers, P.D., 2005. Genome-wide expression profiling of the response to azole, polyene, 480 echinocandin, and pyrimidine antifungal agents in Candida albicans. Antimicrob. Agents Chemother. 49, 2226-2236.

21. Lopez-Ribot, J.L., McAtee, R.K., Lee, L.N., Kirkpatrick, W.R., White, T.C., Sanglard, D., Patterson, T.F., 1998. Distinct patterns of gene expression associated with development of fluconazole resistance in serial Candida albicans isolates from 485 human immunodeficiency virus-infected patients with oropharyngeal candidiasis. Antimicrob. Agents Chemother. 42, 2932-2937. 
22. Mateus, C., Crow, S.A. Jr., Ahearn, D.G., 2004. Adherence of Candida albicans to silicone induces immediate enhanced tolerance to fluconazole. Antimicrob. Agents Chemother. 48, 3358-3366.

490 23. Mio, T., Yamada-Okabe, T., Yabe, T., Nakajima,T., Arisawa, M., and YamadaOkabe, H., 1997. Isolation of the Candida albicans homologs of Saccharomyces cerevisiae KRE6 and SKN1: expression and physiological function. J. Bacteriol. 179, 2363-2372.

24. Mukherjee, P.K., Chandra, J., Kuhn, D.M., Ghannoum, M.A., 2003. Mechanisms 495 of fluconazole resistance in Candida albicans biofilms: phase-specific role of efflux pumps and membrane sterols. Infect. Immun. 71, 4333-4340.

25. Nailis, H., Coenye, T., Van Nieuwerburgh, F., Deforce, D., Nelis, H.J., 2006. Development and evaluation of different normalization strategies for gene expression studies in Candida albicans biofilms by real-time PCR. BMC Mol. Biol. 7, 25.

500 26. Nailis, H., Vandenbroucke, R., Tilleman, K., Deforce, D., Nelis, H., Coenye, T., 2009. Monitoring ALS1 and ALS3 gene expression during in vitro Candida albicans biofilm formation under continuous flow conditions. Mycopathologia 167, 9-17.

27. Odds, F.C., 1988. Meeting Candida and Candidiosis, $2^{\text {nd }}$ ed. Bailliere Tindall, London, UK.

505 28. Pappas, P.G., Rex, J.H., Sobel J.D., Filler, S.G., Dismukes, W.E., Walsh, T.J., Edwards, J.E., 2004. Infectious Disease Society of Amerika; Guidelines for treatment of candidiasis. Clin. Infect. Dis. 38, 161-189.

29. Ponton, J., Quindos, G., Arilla, M.C., Mackenzie, D.W., 1994. Simplified adsorption method for detection of antibodies to Candida albicans germ tubes. J. 510 Clin. Microbiol. 32, 217-219.

30. Ramage, G., Bachmann, S., Patterson, T.F., Wickes, B.L., López-Ribot, J.L., 2002. Investigation of multidrug efflux pumps in relation to fluconazole resistance in Candida albicans biofilms. J. Antimicrob. Chemother. 49, 973-980.

31. Richardson, K., 1990. The discovery and profile of fluconazole. J. Chemother. 2 , $515 \quad 51-54$.

32. Rogers, P.D., Barker, K.S., 2003. Genome-wide expression profile analysis reveals coordinately regulated genes associated with stepwise acquisition of azole resistance in Candida albicans clinical isolates. Antimicrob. Agents Chemother. 47, 1220-1227. 
520 33. Sanglard, D., 2002. Resistance of human fungal pathogens to antifungal drugs. Curr. Opin. Microbiol. 5, 379-385.

34. Warnock, D.W., 1991. Amphotericin B: an introduction. J. Antimicrob. Chemother. 28, 27-38.

35. White, T.C., 1997. Increased mRNA levels of ERG16, CDR, and MDR1 correlate 525 with increases in azole resistance in Candida albicans isolates from a patient infected with human immunodeficiency virus. Antimicrob. Agents Chemother. 41, 1482-1487. 36. White, T.C., Marr, K.A., Bowden, R.A., 1998. Clinical, cellular and molecular factors that contribute to antifungal drug resistance. Clin. Microbiol. Rev. 11, 382402.

530 37. White, T.C., Holleman, S., Dy, F., Mirels, L.F., Stevens D.A., 2002. Resistance mechanisms in clinical isolates of Candida albicans. Antimicrob. Agents Chemother. 46, 1704-1713.

38. Zhao, X., Daniels, K.J., Oh, S.H., Green, C.B., Yeater, K.M., Soll, D.R., Hoyer, L.L., 2006. Candida albicans Als3p is required for wild-type biofilm formation on 535 silicone elastomer surfaces. Microbiology 152, 2287-2299. 


\section{Legends to figures}

Fig. 1: CLSM images of C. albicans SC5314 biofilms grown for $1 \mathrm{~h}$ (Fig. $1 \mathrm{~A})$ and 24 h (Fig. $1 \mathrm{~B}$ ) on silicone disks in 24-well microtiter plates. CLSM images of mature $C$.

540 albicans SC5314 biofilms (72 h) treated for $22 \mathrm{~h}$ with $1000 \mathrm{mg} / \mathrm{l}$ of FLC (Fig. 1C) or with $32 \mathrm{mg} / \mathrm{l}$ of $A M B$ (Fig. 1D). Sessile C. albicans cells were stained with Concanavalin A, resulting in red labelled cells and red stained extracellular matrix. Scale bar: $10 \mu \mathrm{m}$.

545 Fig. 2: Average gene expression levels in young $(1 \mathrm{~h})$ C. albicans SC5314 biofilms after exposure to low doses of FLC $(0.5 \mathrm{mg} / \mathrm{l})$ for $22 \mathrm{~h}$. Gene expression levels (fold up- or downregulation) were defined as the expression of a gene in biofilms treated with FLC, relative to its expression in untreated biofilms. * represents statistically significant difference in gene expression between biofilms treated with FLC and untreated biofilms $(p<0.05)$. 


\section{Tables}

Table 1: Sequences of primers and MGB Taqman probes for $C$. albicans genes used in the real-time PCR assays.

555

\begin{tabular}{|c|c|c|c|}
\hline Gene & Protein product and/or function & Orientation & Sequence ( $5^{\prime}$ to $\left.3^{\prime}\right)$ \\
\hline \multirow[t]{3}{*}{$C D R 1$} & \multirow{3}{*}{$\begin{array}{l}\text { ABC membrane transporter involved in active efflux } \\
\text { of a variety of components including antifungal agents }\end{array}$} & Forward & CAGCAACCATGGGTCAATTATG \\
\hline & & Reverse & GTAGCCAAATTGGCAGCATTATC \\
\hline & & Probe & ATGTCTTTCAGTGAATTAG \\
\hline \multirow[t]{2}{*}{ CDR2 } & \multirow{2}{*}{$\begin{array}{l}\text { ABC membrane transporter involved in active efflux of } \\
\text { a variety of components including antifungal agents }\end{array}$} & Forward & GATTCAAGCCATTCTTTCTACTGGAT \\
\hline & & $\begin{array}{l}\text { Reverse } \\
\text { Probe }\end{array}$ & $\begin{array}{l}\text { AGTAACCAATTCTCTAGGTGCACAAG } \\
\text { AGCTAATGCAAAAGTC }\end{array}$ \\
\hline \multirow[t]{3}{*}{ MDR1 } & \multirow{3}{*}{$\begin{array}{l}\text { MF membrane transporter involved in active efflux of } \\
\text { a variety of components including antifungal agents }\end{array}$} & Forward & TTCCGTGTTGGGTTTCATCA \\
\hline & & Reverse & TGGTCCGTTCAAGTAAAACAAAACT \\
\hline & & Probe & CCTTGTTATGATTGCTATTC \\
\hline \multirow[t]{3}{*}{ ERG1 } & \multirow{3}{*}{$\begin{array}{l}\text { Squalene epoxidase, catalyzes epoxidation of } \\
\text { squalene to } 2,3(S) \text {-oxidosqualene }\end{array}$} & Forward & AGAATGTGTTAACGGGCCAATT \\
\hline & & Reverse & ATGGTTGAATAACAACATTGGGAAT \\
\hline & & Probe & ATTATTGAGTGGCATGTTAC \\
\hline \multirow[t]{2}{*}{ ERG3 } & \multirow{2}{*}{$\begin{array}{l}\text { C-5 sterol desaturase; introduction of C-5(6) double } \\
\text { bond into episterol. }\end{array}$} & Forward & GGCCATCTGTTTACAAAGTGTTACA \\
\hline & & $\begin{array}{l}\text { Reverse } \\
\text { Probe }\end{array}$ & $\begin{array}{l}\text { TGAGAAGCAAATGGAGTACAAACAA } \\
\text { AAACCTCATCACAAGTGG }\end{array}$ \\
\hline \multirow[t]{2}{*}{ ERG11 } & \multirow{2}{*}{$\begin{array}{l}\text { Lanosterol } 14-\alpha-\text {-demethylase, member of the } \\
\text { cytochrome P450 family; catalyzes the conversion of } \\
\text { lanosterol }\end{array}$} & Forward & GCTAATTCTGTTTCATTTAACTCTTCTGAT \\
\hline & & $\begin{array}{l}\text { Reverse } \\
\text { Probe }\end{array}$ & $\begin{array}{l}\text { GGTGAAGAAACCCCTTTAGAAACTT } \\
\text { AAGTTGATTATGGGTTTGGG }\end{array}$ \\
\hline \multirow[t]{3}{*}{ ERG25 } & \multirow{3}{*}{$\begin{array}{l}\text { Putative C-4 methyl sterol oxidase, important for C4 } \\
\text { demethylation of ergosterol biosynthesis } \\
\text { intermediates }\end{array}$} & Forward & TATTTCATTGGTGGATACTCTTCATCTT \\
\hline & & Reverse & GGACCAGCTTCGGTATCCAAA \\
\hline & & Probe & TAGATGGTGGGATTTCA \\
\hline \multirow[t]{3}{*}{ KRE1 } & \multirow{3}{*}{$\begin{array}{l}\text { Predicted Glycosyl Phosphatidyl Inositol anchor } \\
\text { protein with a role in } \beta-1,6 \text {-glucan biosynthesis. }\end{array}$} & Forward & CCTTGCGGCAGATAAAACGT \\
\hline & & Reverse & GCATCAGTACCTGTGACCCATACT \\
\hline & & Probe & CAGTTCAGTATCACCTACTT \\
\hline \multirow[t]{3}{*}{ SKN1 } & \multirow{3}{*}{$\begin{array}{l}\mathrm{N} \text {-glycosylated type II membrane protein with a } \\
\text { predicted role in } \beta-1,6 \text {-glucan biosynthesis }\end{array}$} & Forward & CCCTGAAATTGATGCATTGGA \\
\hline & & Reverse & CATAAGGAGCAACTTGTAATGATTGAG \\
\hline & & Probe & TTCATGGTGTTATAGGTAGAGTT \\
\hline
\end{tabular}


Table 2: Average number of sessile $C$. albicans SC5314 cells (CFU/disk) in untreated biofilms and in biofilms treated for $1 \mathrm{~h}$ or $22 \mathrm{~h}$ with FLC $(1000 \mathrm{mg} / \mathrm{l})$ or AMB $(32 \mathrm{mg} / \mathrm{l})$.

\section{Average number of sessile C. albicans cells ( $\log _{10} \mathrm{CFU} / \mathrm{disk}$ )}

\begin{tabular}{|c|c|c|c|c|c|c|c|c|c|}
\hline \multicolumn{2}{|c|}{ Untreated } & \multicolumn{2}{|c|}{ Treated with FLC (1 h) } & \multicolumn{2}{|c|}{ Treated with FLC (22 h) } & \multicolumn{2}{|c|}{ Treated with AMB (1 h) } & \multicolumn{2}{|c|}{ Treated with AMB $(22 \mathrm{~h}$} \\
\hline Age (h) & $\mathrm{CFU}^{\mathrm{a}}$ & $\mathrm{CFU}^{\mathrm{a}}$ & Reduction $^{\mathrm{b}}$ & $\mathrm{CFU}^{\mathrm{a}}$ & Reduction $^{\mathrm{b}}$ & $\mathrm{CFU}^{\mathrm{a}}$ & Reduction ${ }^{\mathrm{b}}$ & $\mathrm{CFU}^{\mathrm{a}}$ & Reduction $^{\mathrm{b}}$ \\
\hline 0.5 & $4.4 \pm 0.4$ & ND & ND & $4.5 \pm 0.6$ & -0.1 & ND & ND & $3.0 \pm 0.9$ & $1.4^{\mathrm{C}}$ \\
\hline 1 & $4.7 \pm 0.4$ & $4.3 \pm 0.4$ & 0.4 & $4.4 \pm 0.7$ & 0.3 & $2.4 \pm 0.7$ & $2.3^{c}$ & $3.2 \pm 0.7$ & $1.5^{\mathrm{C}}$ \\
\hline 24 & $6.8 \pm 0.3$ & $6.4 \pm 0.4$ & 0.4 & $6.8 \pm 0.4$ & 0 & $4.6 \pm 0.3$ & $2.2^{c}$ & $4.5 \pm 0.6$ & $2.3^{c}$ \\
\hline 72 & $6.8 \pm 0.3$ & ND & ND & $6.5 \pm 0.4$ & 0.3 & ND & ND & $4.5 \pm 0.4$ & $2.3^{c}$ \\
\hline
\end{tabular}

${ }^{a} \log _{10}$ average number of CFU/disk \pm SD $(n \geq 12)$

$560{ }^{\mathrm{b}} \log _{10}$ reduction of cells after treatment, compared to the cell number of untreated biofilms at the same stage of growth.

${ }^{c}$ Reductions were considered biologically relevant when a statistically significant reduction $(p<0.05)$ of at least $1 \log _{10}$ unit was observed; ND = Not determined. 
Table 3: Average gene expression levels (with corresponding SEM; $\mathrm{n}=3$ ) in young $(0.5 \mathrm{~h}$ and $1 \mathrm{~h})$ and mature (24 $\mathrm{h}$ and $72 \mathrm{~h}) \mathrm{C}$. albicans SC5314 biofilms after exposure to high doses of FLC (1000 mg/l). Gene expression levels (fold up- or downregulation) were defined as the expression of a gene in biofilms treated with FLC for $1 \mathrm{~h}$ or $22 \mathrm{~h}$, relative to its expression in untreated biofilms.

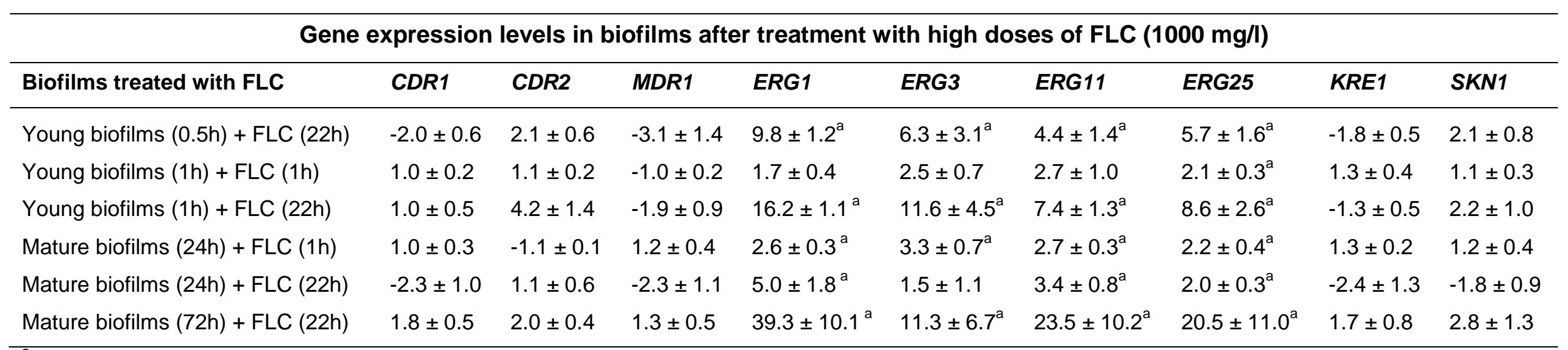

${ }^{a}$ Statistically significant difference in gene expression between biofilms treated with FLC and untreated biofilms $(p<0.05)$. 
Table 4: Average gene expression levels (with corresponding SEM; $\mathrm{n}=3)$ in young $(0.5 \mathrm{~h}$ and $1 \mathrm{~h})$ and mature $(24 \mathrm{~h}$ and $72 \mathrm{~h}) \mathrm{C}$. albicans SC5314 biofilms after exposure to high doses of AMB (32 mg/l). Gene expression levels (fold up- or downregulation) were defined as the expression of a gene in biofilms treated with $A M B$ for $1 \mathrm{~h}$ or $22 \mathrm{~h}$, relative to its expression in untreated biofilms.

\begin{tabular}{lllllll}
\hline \multicolumn{6}{c}{ Gene expression levels in biofilms after treatment with high doses of AMB (32 mg/l) } \\
\hline Biofilms treated with AMB & ERG1 & ERG3 & ERG11 & ERG25 & KRE1 & SKN1 \\
\hline Young biofilms (0.5h) + AMB (22h) & $3.8 \pm 2.0^{\mathrm{a}}$ & $2.5 \pm 1.7$ & $1.2 \pm 0.3$ & $1.7 \pm 0.9$ & $1.9 \pm 1.3$ & $40.0 \pm 32.1^{\mathrm{a}}$ \\
Young biofilms (1h) + AMB (1h) & $-1.4 \pm 0.3$ & $1.3 \pm 0.3$ & $-1.3 \pm 0.5$ & $1.0 \pm 0.3$ & $6.6 \pm 2.1^{\mathrm{a}}$ & $16.0 \pm 6.6^{\mathrm{a}}$ \\
Young biofilms (1h) + AMB (22h) & $3.5 \pm 1.9^{\mathrm{a}}$ & $2.1 \pm 1.5$ & $1.2 \pm 0.3$ & $1.9 \pm 1.0$ & $1.1 \pm 0.6$ & $22.4 \pm 12.9^{\mathrm{a}}$ \\
Mature biofilms (24h) + AMB (1h) & $-2.2 \pm 0.2$ & $1.1 \pm 0.1$ & $-1.8 \pm 0.2$ & $-1.3 \pm 0.3$ & $4.9 \pm 1.3^{\mathrm{a}}$ & $13.0 \pm 3.1^{\mathrm{a}}$ \\
Mature biofilms (24h) + AMB (22h) & $4.1 \pm 1.4^{\mathrm{a}}$ & $1.3 \pm 0.7$ & $1.2 \pm 0.4$ & $2.3 \pm 1.0$ & $5.7 \pm 2.4^{\mathrm{a}}$ & $59.9 \pm 17.5^{\mathrm{a}}$ \\
Mature biofilms (72h) + AMB (22h) & $-1.6 \pm 1.4$ & $-4.2 \pm 2.4$ & $-2.4 \pm 1.7$ & $-2.0 \pm 1.3$ & $1.4 \pm 0.5$ & $21.8 \pm 6.1^{\mathrm{a}}$ \\
\hline
\end{tabular}

${ }^{a}$ Statistically significant difference in gene expression between biofilms treated with AMB and untreated biofilms $(p<0.05)$. 
Table 5: Average gene expression levels (with corresponding SEM; $n=3$ ) in C. albicans SC5314 biofilms regrown in antifungal-free medium after exposure to high doses of FLC (1000 mg/l) or AMB (32 mg/l). Gene expression levels (fold up- or downregulation) were defined as the expression of a gene in biofilms after $1 \mathrm{~h}$ or $24 \mathrm{~h}$ of regrowth, relative to its expression in biofilms after treatment with antifungal agents.

\section{Gene expression levels in biofilms after removal of the antifungal agent}

\begin{tabular}{|c|c|c|c|c|c|c|c|c|c|}
\hline Biofilms after regrowth & $C D R 1$ & $C D R 2$ & MDR1 & ERG1 & ERG3 & ERG11 & ERG25 & $K R E 1$ & SKN1 \\
\hline FLC $+1 \mathrm{~h}$ regrowth & $1.4 \pm 0.4$ & $2.7 \pm 2.4$ & $3.5 \pm 2.4$ & $-2.9 \pm 0.6$ & $-2.6 \pm 0.6$ & $-3.6 \pm 0.7$ & $-1.6 \pm 0.4$ & $3.1 \pm 0.8$ & $49.6 \pm 9.2^{a}$ \\
\hline$F L C+24 h$ regrowth & $2.8 \pm 0.4$ & $2.2 \pm 0.7$ & $5.3 \pm 2.0$ & $1.2 \pm 0.2$ & $2.4 \pm 0.4$ & $1.0 \pm 0.1$ & $2.9 \pm 0.6$ & $4.6 \pm 1.3$ & $31.7 \pm 6.6^{\mathrm{a}}$ \\
\hline$A M B+1 h$ regrowth & ND & ND & ND & $-1.4 \pm 0.7$ & $-1.5 \pm 0.5$ & $-1.9 \pm 0.1$ & $-1.4 \pm 0.4$ & $2.2 \pm 0.8$ & $4.6 \pm 1.2^{\mathrm{a}}$ \\
\hline $\mathrm{AMB}+24 \mathrm{~h}$ regrowth & ND & ND & ND & $2.5 \pm 1.5$ & $2.4 \pm 1.5$ & $1.1 \pm 0.4$ & $2.5 \pm 1.2$ & $3.7 \pm 1.6$ & $3.8 \pm 1.6$ \\
\hline
\end{tabular}

${ }^{a}$ Statistically significant difference in gene expression between biofilms after regrowth and biofilms after treatment (p<0.05). ND: Not determined 